REVISTA ANDALUZA DE ANTROPOLOGÍA

NÚMERO 13:

SEPTIEMBRE DE 2017

ISSN 2174-6796

[pp. 85-111]

http://dx.doi.org/10.12795/RAA.2017.13.04

Fecha de Recepción: 20/07/2017

Fecha de Aceptación: 05/09/2017

\title{
¿ES FEMINISTA PARIR EN CASA? DILEMAS Y CONTRADICCIONES EN LA RELACIÓN ENTRE FEMINISMO Y PARTO EN CASA
}

\section{IS GIVING BIRTH AT HOME A FEMINIST ACT? DILEMMAS AND CONTRADICTIONS IN THE RELATIONSHIP BETWEEN HOME BIRTH AND FEMINISM}

\section{Serena Triuzzi}

Universidad de Sevilla

\section{Resumen}

En el Estado español, a partir de mediados de los años 70 del siglo XX los nacimientos se dieron casi exclusivamente en hospitales y clínicas. Desde entonces la atención domiciliaria al parto pasó a ser considerada una práctica anticuada y arriesgada. Y desde entonces, principalmente en respuesta a demandas e inquietudes que nacieron en el seno de movimientos sociales contestatarios, también se fue definiendo como modelo de atención alternativo y con características propias. En particular, influyeron en su desarrollo los planteamientos teóricos y activistas feministas que, en los aspectos relativos a la salud de las mujeres, permitieron denunciar graves ausencias en los sistemas sanitarios; generar críticas numerosas y contundentes a la biomedicina; y crear formas alternativas y afirmativas de atención, como los grupos de autoconocimiento corporal y autogestión de la salud. El presente artículo, sirviéndose de fuentes de archivo y de datos recopilados en la Comunidad Autónoma de Andalucía, pretende ahondar en las 
contradicciones y en los dilemas que plantea al feminismo la atención domiciliaria al parto.

\title{
Palabras clave
}

Parto en casa, feminismo, matronas, atención perinatal, salud de las mujeres.

\begin{abstract}
In the Spanish state, starting from the mid-1970s, births have been almost exclusively carried out in hospitals and clinics. Indeed, home birthing came to be considered an outdated and risky practice. However, since then, mainly in response to demands and concerns that arose from social movements, home birthing has been defined as a model of alternative care with its own characteristics. In particular, theoretical approaches and feminist activists influenced its development, which, in terms of women's health, made it possible to denounce serious shortcomings in the health systems; generate numerous and compelling criticisms of biomedicine; and create alternative and affirmative forms of care, such as groups centered on body self-knowledge and the self-management of health. The present article, using archival sources and data collected in the Autonomous Community of Andalusia, seeks to delve into the contradictions and dilemmas that home births pose for feminism.
\end{abstract}

\section{Key words}

Home birth, feminism, midwives, perinatal care, women's health.

\section{INTRODUCCIÓN}

Parir en casa ha sido un hecho común en Europa occidental hasta bien entrado el siglo XX. En la asistencia, a pesar de la incipiente afirmación de la actividad obstétrica médica en las cortes y entre las clases altas ya a partir de los siglos XVII y XVIII, las matronas mantuvieron un papel central que se prolongó durante más tiempo en las zonas rurales, aunque su hacer fue progresivamente marcado por las definiciones biomédicas (Montes et al. 2013, Orrú 1993, Triolo 1994, Mocci 1993, Ortiz 1999).

Así, en el Estado español la asistencia domiciliaria efectuada por una matrona era la práctica dominante en la primera mitad del siglo XX (Montes et al., 2013) y se canalizaba a las parturientas a clínicas y casas de maternidad exclusivamente en caso de complicaciones durante el embarazo o de «distocia social» (id.: 182), un eufemismo usado para definir los casos de pobreza extrema. La atención hospitalaria al parto empezó a difundirse solamente en los años sesenta y setenta, consiguiendo incluir a la población rural más alejada para finales de los años setenta (Lellep, 1980). No obstante, todavía 
en 1976 el 17\% de los partos acontecía en el propio domicilio (de Miguel, 1980)ํ. Muy probablemente una erradicación total de la práctica de parir en casa no llegó a darse en ningún momento, al menos no de manera uniforme en todo el país. Lo que es cierto, en todo caso, es que se produjo un paulatino desplazamiento de la casa al hospital como lugar para dar a luz y, por tanto, como lugar de formación y de trabajo para las matronas, hasta constituir actualmente los partos domiciliarios menos del 1\% del total en el Estado (Euro-peristat, 2013).

A lo largo del presente artículo nos ocuparemos exclusivamente del parto en casa como modelo de atención particular que empieza a construirse después de la difusión masificada del parto hospitalario, entre finales de los años setenta y principios de los ochenta, como reacción al manejo tecnomédico de todo el proceso. Modelo que guarda escasas relaciones con las modalidades antecedentes al boom hospitalario, en parte por la casi absoluta falta de contacto con las matronas de generaciones anteriores, en parte por constituir un cuestionamiento activo de algunas prácticas biomédicas rutinarias. En este sentido, no supone solo un cambio de lugar con respecto al dominante, sino que propone unos modos profundamente distintos a los hospitalarios. Tiene que enfrentarse, además, a las opiniones biomédicas hegemónicas que lo consideran algo anticuado e inútilmente arriesgado, tal y como muestran las declaraciones de los últimos diez lustros de eminentes ginecólogos y de los propios representantes de la Sociedad Española de Ginecología y Obstetricia (SEGO), la máxima autoridad en materia obstétrico-ginecológica a nivel estatal ${ }^{2}$. Cabe señalar, por último, a fin de encuadrar los argumentos que nos disponemos a presentar, que este modelo, que ha seguido desarrollándose hasta la actualidad, incluye tanto la fase anterior como la posterior al nacimiento, en una visión unitaria y compleja del embarazo/parto/posparto (de aquí en adelante, epp).

La expresión parto en casa, en definitiva, se utilizará para indicar un modelo de atención con características propias, cuyas bases se establecen en un momento y en un contexto particulares y en el cuadro de determinados movimientos sociales, entre los que destacamos el movimiento feminista. El objetivo será el de visibilizar y problematizar los nexos entre este modelo de asistencia y el feminismo. La pregunta que encabeza este texto es evidentemente una pregunta provocadora que retoma el título de una comunicación

1. El autor no distingue entre zonas rurales y urbanas, ni entre distintas Comunidades Autónomas.

2. Esta afirmación está basada en el examen de documentos de archivo relativos a los inicios del parto en casa y en la revisión sistemática de artículos de opinión publicados en internet en los años en los que se ha venido desarrollando la investigación (2013-2016). La última de estas declaraciones es la de Txantón Martínez-Astorquiza, elegido como presidente de la SEGO en julio de 2015: «Desde el punto de vista médico, actualmente yo creo que no es recomendable el parto en casa. Si el parto es superrápido e inminente y no lo puedes evitar, por supuesto te quedas en tu casa, llamas a una ambulancia o que alguien te ayude. Pero en general, ahora se puede acudir a los hospitales con libertad. Y yo creo que es lo adecuado» (http://farmacosalud.com/desde-el-punto-de-vista-medico-es-recomendable-el-parto-encasa/). 
presentada por la autora en $2016^{3}$ y que no pretende ser respondida sino iniciar una reflexión. Para ello empezaremos centrándonos en los (re)inicios del parto en casa en el Estado español, en los que estos nexos son bastante evidentes, para llegar finalmente a discutir su manifestación actual, sirviéndonos de datos recopilados en Andalucía. La base de las páginas que siguen a continuación es la investigación desarrollada entre 2013 y 2016 para mi tesis doctoral, la cual se ocupa de las maneras en las que se configura la atención domiciliaria al parto en la Comunidad de Andalucía, indagando en sus orígenes y en sus relaciones con el contexto sanitario general ${ }^{4}$.

\section{LOS NEXOS ENTRE FEMINISMO Y PARTO EN CASA A FINALES DEL SIGLO XX}

La asistencia domiciliaria al parto de finales del siglo pasado nace como reacción a los excesos tecnomédicos, común a distintos contextos europeos y norteamericanos, pero también como proceso afirmativo, en la medida en que aparece íntimamente ligado a las reivindicaciones feministas de control sobre el cuerpo y los procesos reproductivos y a las prácticas de autogestión de la salud con ellas relacionadas.

Así, en el Estado español, las profesionales, matronas en gran mayoría, que se dedicaron a asistir en casa en las últimas tres décadas del siglo XX respondían a la demanda de mujeres que no estaban satisfechas con el tipo de atención que se proporcionaba en hospitales y clínicas, y que buscaban algo profundamente distinto. Con ellas compartían motivaciones e inquietudes que surgieron en el seno de movimientos sociales contestatarios que, de manera general, se caracterizaban por cuestionar las relaciones de

3. El presente artículo es una versión más elaborada de una comunicación presentada en el panel «Género y feminismo», en el marco del II Congreso Internacional de Antropología AIBR, celebrado en Barcelona en 2016. Su título completo es ¿Es parir en casa feminista? Algunas reflexiones a partir de la atención domiciliaria al parto en Andalucía. Los numerosos comentarios que siguieron a su exposición vinieron a confirmar no solamente el interés del tema propuesto sino la necesidad de abrir un debate. Aquí se recogen, en la medida de lo posible, las sugerencias de las personas presentes y se incorporan también algunas conclusiones posteriores de la investigación.

4. El título del proyecto de investigación es el siguiente: Parir en casa. Un estudio antropológico de la atención domiciliaria al parto en el contexto andaluz. Para llevarlo a cabo se consideró indispensable recurrir a una multiplicidad de fuentes y técnicas, incluyendo una parte de trabajo de archivo, enfocado básicamente a un examen de los documentos elaborados desde la década de los 80 del siglo XX por la Asociación Nacer en Casa; otra de entrevistas a miembros de los equipos de atención domiciliaria en activo en el territorio de Andalucía, y madres y padres que decidieron dar a luz a sus hijos en casa; y una última de observación en cursos prenatales ofertados por un centro especializado en asistencia al parto en casa. Todo ello se complementó con la revisión de leyes, estrategias estatales y autonómicas que regulan la atención perinatal, guías de práctica clínica, e informes sanitarios, lo que permitió ir definiendo el actual marco teórico-normativo de la asistencia al embarazo, parto y posparto en el Estado español.

Con respecto a las entrevistas, se ha realizado un total de 60, 26 a profesionales (matronas en gran mayoría, por ser las que se dedican en gran medida a la asistencia domiciliaria y, más en general, a lo que se considera fisiológico o normal en el embarazo, parto y posparto), 32 a madres y padres, y 2 a representantes de las Asociaciones Nacer en Casa y El Parto Es Nuestro. 
poder y las desigualdades operativas en distintos ámbitos, especialmente en las relaciones sociales de sexo.

Nació así, principalmente como un intento de construir otras relaciones en el epp, un intento que unió a comadronas y mujeres sin formación sanitaria en grupos de preparación a lo largo del embarazo. Recordamos que continúan con algunos cambios hasta el día de hoy, entre los proyectos de más larga duración, el Grup de parts de Barcelona, núcleo originario de la actual Titania dones per la salut; el colectivo de salud Acuario, en la Comunidad valenciana, del que surgió la clínica homónima; y el grupo Génesis de Madrid.

En la ponencia inaugural del Congreso por el 25 aniversario de la Asociación Nacer en Casa (2013) se traza un recorrido de dicha asociación, cuya importancia en la labor de construcción y defensa del modelo domiciliario expondremos a continuación. María Fuentes, una de sus fundadoras y figura emblemática para los desarrollos del parto en casa, propulsora de varios proyectos de formación, divulgación y asistencia, antes en Cataluña y luego en Andalucía, explica que la Asociación se presenta como «la punta de iceberg», una manifestación concreta de un movimiento que se gestó en un momento históricopolítico determinado que se ubicaría en el periodo posfranquista, en una época en la que la asistencia hospitalaria al parto ya se había afirmado de manera incontrovertible y aparentemente irreversible, y en la que la subordinación de la matrona dentro de la organización jerárquica de cada hospital se había hecho explícita ${ }^{5}$. La asistencia domiciliaria al parto nace, por tanto, a partir de una crítica que es eminentemente política y que se refleja en las palabras de esta matrona:

Y en este momento, que coincide con una etapa determinada española más agresiva a nivel político y tal, pues forma parte también de una reivindicación contra el sistema, ¿no? el yo decido -quizás- hacerlo de otra manera, ¿no? Entonces hay mujeres, parteras que se forman fuera y de manera autodidacta para seguir asistiendo a las mujeres en casa porque [...], porque era un derecho de la mujer, uno de los derechos que se habían cepillado, como otras tantas cosas. [Patricia, 43 años]

En varios documentos, escritos y orales, profesionales - matronas y algunas médicasque vivieron esta fase identifican en la filosofía y militancia de la no-violencia y en el feminismo las raíces personales y también colectivas de su trabajo en la asistencia al parto en casa. En palabras de María Fuentes, en el mencionado Congreso:

Eran movimientos políticos que obviamente se oponían a la dictadura y al fascismo, por las libertades, y en este contexto sobre todo desde los ámbitos de la no violencia y

5. Véase el Estatuto del personal sanitario no facultativo de las instituciones sanitarias de la Seguridad Social, de 1973. 
desde los ámbitos del feminismo nos fuimos encontrando, nunca por casualidad, pero aparentemente por casualidad, algunas de nosotras [María Fuentes, audio Congreso, 2013].

Sin embargo, si la inclusión en el seno de los movimientos de la no-violencia fue fácil, deviniendo el texto del obstetra francés Leboyer (1983 [1974]) Por un nacimiento sin violencia una especie de carta de presentación para las que se dedicaban a asistir partos no medicalizados, definirse como feministas no resultó igualmente aproblemático. Así, en los relatos de inicio de quienes participaron en esta fase del parto en casa, se admite la dificultad de ser reconocidas como feministas por ciertos sectores del feminismo:

[...] yo me siento privilegiada en esto, de haber estado en los inicios de un movimiento feminista que como te decía antes el tema de la maternidad era como algo intocable y de hecho nos criticaban muchísimo, al pequeñísimo colectivo que éramos nosotras. Yo siempre digo que yo estaba siempre en tierra de nadie, ¿no? Vamos yo y creo que alguna demás de mis colegas, pero yo me sentía entre las feministas me miraban de reojo porque no me consideraban feminista digamos ortodoxa [...] [Isabel, 57 años].

El conocimiento de y el control sobre los procesos reproductivos pueden considerarse indiscutibles baluartes del movimiento y de las teorías feministas, estando en el centro de debates, críticas y acciones en varios países de Europa occidental y Norteamérica ya a partir de la década de los setenta. No obstante, estas cuestiones esconden ciertas ambivalencias y producen tensiones internas al propio feminismo, en parte compartidas más allá de los confines estatales, en parte muy características del contexto histórico del Estado español. En este, la evidente desigualdad entre hombres y mujeres establecida legalmente y en distintos campos durante el franquismo (Valiente, 2003) imponía luchas urgentes para las mujeres, para tener acceso a la educación y al empleo (sin depender de ningún permiso marital) o poder decidir cuándo y si tener progenie. El distanciamiento del feminismo de la maternidad como dimensión definitoria de las mujeres y como destino pasó por su negación (teórica) y su arrinconamiento (social), dando prioridad a la conquista de la esfera pública. Ahora bien, si el feminismo puede caracterizarse por algo es por la gran variedad de posturas internas, frecuentemente simultáneas, y la capacidad de autocrítica que, si no siempre, al menos a menudo ha generado fértiles debates y no solamente estériles confrontaciones. La maternidad, así, como institución social, como opción individual y como fase común en la vida de muchas mujeres, ha constituido durante mucho tiempo un importante núcleo de debate.

Merece la pena detenerse en dos textos de finales de los años setenta y principios de los ochenta, ambos producidos por el grupo catalán DAIA (Dones per l'autoconeixement i l’anticoncepció), el cual unía a mujeres profesionales y no profesionales de la salud. 
Rescatar sus propuestas nos parece importante porque nos permite dar cuenta de la heterogeneidad de las reivindicaciones y luchas feministas de la época. Si podemos coincidir con otras autoras que señalan la prioridad concedida por el movimiento feminista a aspectos ajenos al epp, en un contexto en el que urgía desmarcarse de una visión de la maternidad como dimensión definitoria para las mujeres, y conseguir ser reconocidas como sujetos de derecho, el parto en casa ofrece una perspectiva sugestiva para conseguir una visión más compleja del panorama feminista de la época. Así, si además es cierto que en el ámbito de la salud gran parte de los esfuerzos del movimiento feminista en el Estado español se centraron en la difusión de la anticoncepción y en la despenalización del aborto ( $c f$. Ferreira, 2008), no habría que olvidar que coexistieron distintos objetivos de lucha, por la propia variabilidad de situaciones experimentadas, en aquella íntima conexión entre pensamiento y vida tan característica del feminismo. No sería tan sencillo, en definitiva, identificar un sucederse lineal de posturas del feminismo español con respecto a la maternidad ni de corrientes feministas representativas de cada época (Aler, 2012) ${ }^{6}$.

En un sulfuroso texto de 1979, las mujeres de DAIA denuncian, a partir de sus propias experiencias y con una ironía demoledora, la problemática ausencia de la maternidad en los círculos feministas en los que se movían o su reducción a cómo poder limitarla o evitarla. Sin caer nunca en una exaltación de la maternidad pero sí negándose rotundamente a su olvido, a partir de la constatación innegable de su realidad empírica, prefieren bajar a una dimensión más terrenal, tratándola como posibilidad inmanente y no como un mito «al que adorar u odiar». Plantean, entonces, el desafío de transformarla en una opción placentera, una elección personal y militante de ser «madres egoístas», es decir madres para las que el bienestar propio y el del hijo o de la hija no estén necesariamente enfrentados. Para ello consideran necesario incorporar la infancia a la sociedad, a los colectivos feministas y a la vida adulta en general, sin ver en las personas más pequeñas solamente unos seres molestos y siempre fuera de lugar, y apuestan por compartir las tareas de cuidado. Pero también, y se centran en este aspecto, consideran imprescindible recuperar el control sobre todo el proceso reproductivo, a partir, precisamente, del embarazo, parto y posparto. El inicial grito de alarma con el que abren el texto va tomando la forma de una denuncia argumentada del sistema hospitalario, de su rutinaria e iatrogénica cadena de intervenciones, para terminar con una presentación del parto en casa como «contestación radical al actual sistema obstétrico» (documento inédito, s. p.).

«No somos pocas las feministas que vivimos en la contradicción de estar en la sociedad machista aceptadas como madres y negadas en nuestras demás facetas, y de estar en

6. Esta autora propone una clasificación que, en nuestra opinión, produciría una generalización excesiva. En concreto, divide entre feminismo de la igualdad/años 70 y $80 /$ rechazo de la maternidad; feminismo de la diferencia/años 80 y 90/valoración del potencial creador de la maternidad; ecofeminismo/actualidad/ maternidad como forma de vinculación social que trasciende el modelo individualizado de cuidados. 
el movimiento aceptadas en todas nuestras facetas pero ignoradas como madres» (id., s. p.). A partir de esta contradicción vivida, proponen una reflexión sobre lo absurdo de muchos procedimientos hospitalarios $y$, acto seguido, narran sus experiencias en los partos en casa, propios y atendidos. Adelantando las muy probables acusaciones de estar proponiendo un regreso al pasado, toman distancia de un parto domiciliario igualmente dependiente de la figura profesional, caracterizado por el desconocimiento y por el miedo, como puede haber sido el de la generación de sus madres, y puntualizan que no pretenden renunciar a los adelantos tecnológicos de los hospitales, sino emplearlos exclusivamente en caso de necesidad y en los embarazos que se consideran de alto riesgo. En su visión y en su práctica, parir en casa significa tomar las riendas del proceso, aun sabiendo lo difícil que es liberarse de mecanismos tan interiorizados que «hasta las más críticas vamos al parto confiadas y aliviadas ante la idea de que el obstetra va a hacer todo el trabajo» (id., s. p.). La prioridad de los deseos y elecciones de la mujer embarazada requiere además de cierta humildad por parte de comadronas y médicos, quienes devendrían en simples asesores técnicos. De hecho, interpretar el parto en casa como una forma de «contestación radical» tal y como ellas hacen, se debe no solo, o no tanto, a la drástica reducción de intervenciones, sino al sustancial cambio de papeles entre quien asiste y quien es asistida.

Su planteamiento crítico hacia la biomedicina como institución que ha jugado un papel clave en la opresión específica de las mujeres se convierte en autocrítica en otro texto, Reflexiones sobre una experiencia, de 1981, introductorio a la versión en castellano de un trabajo de Barbara Ehrenreich y Deirdre English (Brujas, comadronas y enfermeras. Historias de las sanadoras). La reflexión se centra aquí en los límites de los grupos, como al que ellas pertenecen, que se dedican a dar informaciones muy necesarias sobre anticonceptivos y abortos, pero que son incapaces de salir del tecnicismo para incluir otros aspectos importantes y que reproducen, en último término, la delegación en las figuras expertas. Consideran estas soluciones el fruto de «necesidades inmediatas y parciales», pero reformistas en la medida en que no socavan la dependencia de la persona en relación a quienes poseen conocimientos médicos especializados. Al contrario, ven en los grupos de autoconocimiento y apoyo mutuo, en los partos naturales y en los nacimientos sin violencia, prácticas subversivas y transformadoras, ya que cuestionan verdades biomédicas profundamente enraizadas, demostrando la inutilidad de muchos procedimientos, desenmascarando las ideologías que los impulsan y reapropiándose de procesos vitales no patológicos. En todas estas prácticas, la autonomía de las mujeres en sus decisiones y la capacidad de escuchar y dejar actuar al cuerpo, como sujeto y 
no solamente objeto de múltiples intervenciones, son aspectos de primaria importancia para llevarlas a cabo.

Los textos mencionados nos permiten subrayar, por un lado, la presencia de reflexiones sobre los modos de la asistencia al epp y las vivencias de maternidad ya en la época que nos ocupa y, por otro, la no incompatibilidad entre luchas por el control de la fertilidad y reivindicaciones de maneras más autónomas y gozosas de gestar y parir. Se plantea, de hecho, la indisolubilidad entre decisiones sobre el si y el cuándo de la concepción, y el cómo de su puesta en acto. Proyectos como el Centro de Salud Adriano, que funcionó durante los años ochenta en Sevilla, o el Colectivo de Salud Acuario en la Comunidad Valenciana, que se fundó a principios de los años ochenta y sigue como clínica en la actualidad, comprobarían estas profundas conexiones al practicar tanto abortos (en un momento en que eran ilegales) como partos no violentos, en centros o domicilios particulares (Taboada, 2012). Quienes impulsaron estos proyectos compartían una visión de la salud basada en la autonomía y la autogestión; prácticas feministas como los talleres de autoconocimiento; y unían personas profanas y profesionales de la biomedicina, en el común intento de retomar un «protagonismo vital» que se consideraba políticamente fundamental. No sorprende, por tanto, que en los encuentros previos al parto se enseñara y se invitara a la autoexploración, se explicase al padre ( $u$ a otra persona acompañante) cómo controlar el latido fetal y que pudiesen incluso darse informaciones muy claras sobre cómo hacer frente a un parto que se desencadenara muy rápido, sin auxilio de profesionales especializados (vv. aa., 1988 [1982]). En esta época, además, en lo que se refiere al parto en casa, se asistió a una construcción colaborativa de modos de hablar y de hacer en la que la Asociación Nacer en Casa tuvo un papel central, facilitando los encuentros periódicos entre matronas de distintos lugares y el intercambio de opiniones e informaciones a través de cartas y boletines. Esta Asociación, que sigue existiendo en la actualidad, se creó a finales de los años ochenta pretendiendo agrupar a las personas que estaban trabajando en este sector a nivel estatal. A pesar de no incluir a todas las matronas y médicas/os que asistían en casa en esa época, consiguió reunir a profesionales que actuaban en territorios muy alejados entre sí. Sus socias participaron en talleres, jornadas, visitas a proyectos clínicos de otros países europeos y encuentros sobre atención perinatal, en el ámbito estatal o en la vecina Francia, procurando siempre dar cuenta de sus aprendizajes. Fue un período de gran efervescencia, en el que se tejieron alianzas entre proyectos afines y se fueron definiendo modalidades comunes. La capacidad de autocrítica, el trabajo

7. Una revisión de las actas de asamblea de la Asociación de las últimas dos décadas del siglo pasado, nos informa sobre la procedencia de sus socias. Se mencionan las siguientes Comunidades: Cataluña, País Vasco, Madrid, Castilla-La Mancha, Aragón, Andalucía, Asturias, Galicia, islas Baleares y Canarias. 
incesante de exploración e investigación, y una actitud enormemente receptiva, fueron características esenciales de las matronas que participaron en esta fase del parto en casa ${ }^{8}$.

Tanto las bases teóricas del modelo domiciliario como las prácticas que se fomentaban pueden considerase, en resumidas cuentas, feministas. Sin embargo, cabe señalar también que la tentación de idealizar la maternidad como punto de partida para un nuevo orden moral ha estado muy presente, tanto en el parto en casa como en los desarrollos teóricos feministas, al menos en el denominado feminismo de la diferencia. Desde la idealización de un supuesto pasado ginecocrático-matriarcal a la también supuesta capacidad innata de cuidado femenina, directamente derivada de la fertilidad y de la fuerza reproductora, las caídas esencialistas han sido numerosas y repetidas. Desde la écriture féminine francesa a los enfoques ecofeministas, una identificación demasiado apresurada entre la mujer y la madre ha producido gran cantidad de críticas entre autoras feministas y la necesidad, en más de un caso, de matizar (Mies y Shiva, 1997).

El parto natural, como a menudo se denomina al parto en casa o en centros no hospitalarios, entra en este terreno resbaladizo pudiendo significar cosas muy distintas según situaciones, contextos, ideologías y convicciones personales de distintos autores. Atribuir escaso peso a los aparatos tecnológicos no siempre ha supuesto también un menor protagonismo de las figuras expertas ni ha implicado necesariamente prestar atención a las experiencias de las mujeres. Los peligros de esencialismo o incluso de fomentar visiones claramente conservadoras están ahí y no pueden ignorarse. Veámoslo con más detenimiento, a partir de una revisión de algunos referentes teóricos y de práctica clínica de las matronas de los años ochenta.

\section{LAS REFERENCIAS TEÓRICO-PRÁCTICAS DE LAS MATRONAS DOMICILIARIAS Y LOS PROBLEMAS QUE PLANTEAN DESDE UN PUNTO DE VISTA FEMINISTA}

En palabras de María Jesús Montes, matrona que participó en los (re)inicios del parto en casa, empezar a asistir en los domicilios suponía «inventarse todo» (audio del Congreso para el 25 aniversario de Nacer en Casa, Madrid, 25-26 de mayo de 2013). Efectivamente, el tipo de formación recibido por el personal sanitario estaba enfocado a una atención

8. Por ejemplo, en los documentos más antiguos revisados, producidos por matronas de la Asociación Nacer en Casa entrevistadas en programas radiofónicos, se critica duramente, con subrayados en la transcripción de entrevista y comentarios laterales añadidos con bolígrafo, el haber empleado en las entrevistas un lenguaje paternalista y autoritario; el mostrar una imagen del parto en casa como parto más doloroso; el transmitir la idea de que ninguna parturienta quiere intervenciones, lo que significaría afirmar que en los hospitales se las forzaría siempre, siendo por lo tanto las mujeres simples víctimas sin capacidad de agencia; el presentar a las matronas de parto en casa como «salvadoras»; el utilizar expresiones como «sacar el niño» o «hacer partos»; el usar la primera persona singular (yo) en lugar del plural (nosotros/nosotras) en calidad de portavoces de un colectivo. Todas estas anotaciones demuestran una profunda autorreflexión como grupo, y también la disposición personal a recibir críticas de todo tipo. En documentos posteriores se puede comprobar la asimilación de estas aportaciones. 
altamente sistematizada y tecnologizada, en absoluto aplicable en una casa. Además, las matronas que habían ejercido en la atención domiciliaria en el pasado, antes de ser definitivamente incorporadas a hospitales y clínicas, o se habían jubilado, o eran muy mayores o no tenían contacto con las que decidieron aventurarse en este campo.

Todo ello hizo necesario buscar, en gran medida fuera de los confines estatales, ejemplos y referencias teóricas para asistir al embarazo y al parto, alejándose de los criterios biomédicos establecidos.

En base a los documentos revisados y a las informaciones proporcionadas en entrevistas y conversaciones más informales, podemos identificar dos grandes influencias. La primera está marcada por Grantly Dick-Read en Inglaterra y Fernand Lamaze en Francia, quienes utilizan métodos psicosomáticos de educación prenatal. La segunda, iniciada por Frederick Leboyer y continuada por Michel Odent, se centra en el «cerebro instintivo-emocional». La intención aquí es destacar los puntos de mayor fricción con respecto a los planteamientos feministas, señalando los peligros de esencialismo e incluso conservadurismo de estas teorías.

El ejemplo de Dick-Read, conocido padre del parto sin dolor, resulta revelador para nuestro objetivo. La mayor contribución de este médico inglés, que desarrolló sus teorías en los años treinta del siglo XX, fue sin duda la de introducir la posibilidad y, por tanto, la idea de un parto no doloroso, sin necesidad de métodos analgésicos o anestésicos. Sus observaciones le llevaron a elaborar un método que pretendía, a través de charlas informativas y de técnicas de respiración y relajación, inhibir el miedo que producía la tensión del cuello uterino y, por lo tanto, dolor intenso en las contracciones que preceden el nacimiento ( $c f$. Ruiz, 2009; vv. aa., 1988 [1982]). Es lo que se conoce como triángulo o círculo de Dick-Read, en el que el aumento del miedo produce mayor tensión, que provoca más dolor, y así sucesivamente.

Sin embargo este médico evangélico y reformador social, lejos de querer devolver autonomía a las mujeres en sus partos, estaba movido más bien por intereses eugenésicos, preocupado por la disminución de nacimientos entre la burguesía, y por los destinos de la nación y de la raza inglesa (Moscucci, 2003). Su oposición a las tecnologías biomédicas en el parto, y en particular a la mezcla de escopolamina y morfina que empezaba a tener cierto éxito entre las mujeres de clases más altas, se debía a su inquietud por las nuevas generaciones, por el producto de estos partos, en definitiva, por la futura ciudadanía. Su convicción de que la incorporación de las mujeres al mercado del trabajo en la primera posguerra, junto a un miedo cultural al parto, tenían una función disuasoria en la decisión de embarazarse de las mujeres inglesas de clase media, le impulsó a documentarse sobre las vivencias de parto en otros contextos culturales. A través de viajes y de revisiones bibliográficas, llegó a la conclusión de que las «poblaciones primitivas», en las que luego incluyó a la clase obrera, no sufrían dolor al dar a luz. Proponiendo el tópico del buen 
salvaje y de la corrupción producida por la civilización, en una escala en la que a mayor nivel educativo correspondería mayor sufrimiento en el parto, defendía una educación anterior al parto para poder controlar su desarrollo, sin instrumentos y sin analgesiaanestesia, desde una óptica absolutamente conservadora.

Devolver a las mujeres a la «sagrada llamada» de la maternidad, a su esfera «natural» y a su deber social, junto con la importancia de establecer desde el parto un fuerte y saludable vínculo materno-filial, serían pues los motivos principales del trabajo pionero de este médico inglés. Su objetivo se puede sintetizar en encontrar una solución técnica a lo que considera un fallo social, un daño colateral del progreso social y científico.

Es posible identificar elementos opuestos a los feministas en prácticamente todos los autores/as que sirven de referentes en esta fase de renacimiento del parto. Así, Ferdinand Lamaze, uno de los iniciadores de la psicoprofilaxis obstétrica, se servía de métodos conductistas, en los que la figura médica seguía estando en el centro, dirigiendo un entrenamiento para el control del dolor. Frédérick Leboyer (1983 [1974]), el que acuñó la expresión de nacimiento sin violencia y representó una fuente inspiradora para muchas comadronas, focalizaba su atención exclusivamente en el recién nacido, so pretexto de una supuesta «batalla ya ganada en favor de la madre». La propia Consuelo Ruiz (2008 y 2009), considerada una maestra por las matronas de parto en casa, que cubrió un papel de enlace con las generaciones anteriores y se ocupó de dar difusión al método psicoprofiláctico en el Estado español, defendía la existencia de diferencias esencializadas entre hombres y mujeres, la complementariedad de los sexos, y posturas antiabortistas. Sheila Kitzinger (1988), antropóloga y gran defensora del parto en casa, en la elaboración de su «método psicosexual» identificaba en la maternidad la experiencia cumbre en la vida de las mujeres, además de dirigirse exclusivamente a parejas de clase media, heterosexuales y casadas. Michel Odent $(1984,2001,2008)$, autor popular de numerosos textos divulgativos sobre embarazo y parto, sostenía, y sigue sosteniendo que en un parto los aspectos «mamíferos», animales, instintivos, hormonales son los que verdaderamente cuentan, y que por lo tanto sería conveniente que las mujeres no se informen excesivamente antes de dar a luz. En sus últimos escritos, además, se muestra firmemente convencido de que la Ciencia, como autoridad única y uniforme, y ya no las mujeres y los colectivos de matronas como afirmaba anteriormente, será impulsora de cambios imparables en la forma de nacer, dando también lugar a un salto evolutivo en la humanidad.

¿Cómo encaja todo esto con un parto en casa que se autoproclama feminista y que ve su centro en la autonomía decisional y en la subjetividad corporal?

Los textos de aquellos años nos proporcionan algunas pistas, que las conversaciones con matronas y el conocimiento acumulado en estos años de trabajo de campo confirmarían ampliamente. Aparece con cierta evidencia el uso selectivo de distintas teorías, y de 
herramientas provenientes de múltiples fuentes y áreas de conocimiento. Resumiendo, se usa lo que puede venir bien, independientemente de donde venga, se prescinde de lo que se considera superfluo o que no se comparte. Se generan formas híbridas, una especie de bricolaje de los elementos considerados más adecuados, a menudo insertándolos en prácticas que se distancian netamente, más o menos conscientemente, de las originarias. Así, por ejemplo, de Dick Read se usa el triángulo, de indudable eficacia visual; de Michel Odent se rescatan las explicaciones instintivas y hormonales, pero atribuyéndoles un peso menor del que le atribuía su autor; de Consuelo Ruiz se valora su enorme experiencia, su saber hacer, su convicción y su firmeza en la defensa del parto domiciliario, que reforzaron la confianza de las matronas en las capacidades de las mujeres y en su propio trabajo de asistencia. Y así sucesivamente.

Los deslices esencialistas, no del todo ausentes, parecen en todo caso menos categóricos una vez que se encuadran dentro de un contexto discursivo más amplio. Lo que parece presentar mayores problemas en la actualidad, de hecho, es el progresivo prevalecer de determinados núcleos argumentales, cuya presencia era más bien escasa en los inicios de este modelo de atención, y que como se expone en el siguiente epígrafe, van adquiriendo un espacio y un peso relevantes, al menos a partir del proceso de reforma en la atención perinatal, iniciado en 2007 con la formulación de la Estrategia de atención al parto normal (Ministerio de Sanidad y Consumo).

\section{LA ASISTENCIA DOMICILIARIA AL PARTO EN LA ACTUALIDAD: ¿QUÉ HA SIDO DEL FEMINISMO?}

El parto en casa no puede considerarse, actualmente, un movimiento organizado, ya que existe escaso contacto entre las matronas, estas no constituyen un grupo de presión a nivel institucional, y no se da la misma efervescente construcción colectiva de hace unas décadas. No obstante, al menos en parte de los equipos de trabajo actualmente existentes en Andalucía, se presentan claras continuidades con los inicios descritos en el primer epígrafe, se emplean y se siguen desarrollando modalidades de trabajo que se originaron en aquellos años, y se reconoce además explícitamente su procedencia. Así, por ejemplo, se atribuye una importancia considerable a los encuentros previos al parto con mujeres y parejas, al conocimiento mutuo y a la preparación a lo largo del embarazo; se promueve una visión compleja y multidimensional de la salud; y se hace un uso cuidadoso del lenguaje, señalando repetidamente el protagonismo de mujeres y bebés en el proceso de parir/nacer, y el papel secundario de la matrona. Se identifican, por último, las raíces históricas de este modelo de atención en el Estado español y su conexión con el feminismo, con el movimiento de salud de las mujeres y con la no violencia.

Más en concreto, dentro de la atención domiciliaria al parto en Andalucía, se van configurando dos grandes tendencias, que se reflejan en y son a su vez expresadas por 
opiniones, maneras de hacer y de hablar diferentes. Evidentemente no se trata de una separación neta y dentro de cada equipo de trabajo existe cierta heterogeneidad.

En lo que nos interesa aquí, señalamos que, en una de las dos tendencias, en continuidad con los años ochenta, la asistencia domiciliaria rompe profundamente con la hospitalaria, a través de un cuestionamiento activo de algunos criterios biomédicos comúnmente aceptados, y, más en general, de la visión biomédica de la salud; un uso rupturista y creativo del lenguaje; el empleo de discursos que prefieren prescindir de la «evidencia científica», aunque su uso no se excluya, entre otras cosas, por fines tácticos; y la admisión de otros saberes dentro de su campo profesional e incluso la contribución activa a la difusión de conocimientos especializados. Dentro de esta corriente, por tanto, se sigue desarrollando y considerando fundamentales aquellos aspectos señalados para los orígenes de este modelo de atención, como elementos propulsores del mismo. Entre ellos destacamos: los aspectos no biológicos como primordiales y no auxiliares para la salud; la horizontalidad en la relación entre figuras expertas y personas atendidas; y el énfasis en la capacidad de autogestión y en la importancia del apoyo mutuo. Se trataría pues, a nuestro entender, de la dimensión política feminista del parto en casa, dimensión que queda ampliamente diluida en la otra tendencia identificada. En esta, el ejemplo a seguir y su fuente de legitimación estaría no tanto en los inicios del parto en casa posteriores al boom hospitalario, que por lo general se desconoce o no se menciona, sino más bien en otros sistemas sanitarios de países europeos como Inglaterra y Holanda en los que la opción domiciliaria existe y está cubierta por la sanidad pública, y en los propios documentos de recomendaciones producidos por las instituciones sanitarias estatales y autonómicas a partir de la mencionada Estrategia de atención al parto normal (2007, Ministerio de Sanidad y Consumo). Así, se aceptan en gran parte los criterios incluidos en las guías de práctica clínica hospitalaria, criticando aquellas prácticas obsoletas, que se siguen efectuando a pesar de no estar sostenidas por la última evidencia científica. Dentro de esta corriente, de hecho, el discurso de la evidencia representa la principal razón de sustento de sus prácticas, prevaleciendo sobre cualquier otro motivo discursivo. Desde esta perspectiva se propone una visión del epp centrada fundamentalmente en su desarrollo fisiológico, que el entorno familiar y casero parecen favorecer, y no se discute la superioridad de la autoridad profesional y de las definiciones científicas.

Encontramos, en definitiva, perspectivas bastante distintas, unas más reformistas, que pretenden defender y fomentar aquellas prácticas avaladas por la aparentemente neutral evidencia científica (Triuzzi, en prensa); otras radicalmente críticas y potencialmente transformadoras. Si hemos definido estas últimas como feministas, cabe señalar, sin embargo, que en ambas corrientes se hace un uso más bien escaso y algo confuso del término feminismo, y que ninguna de las matronas entrevistadas se ha servido de la palabra feminista para hablar de sí misma. 
Los ejemplos podrían ser múltiples. Me serviré de uno de ellos, que indica claramente un movimiento oscilatorio, bastante común en la primera de las dos tendencias presentadas, entre atribución de motivos feministas al pasado, su negación en el presente y nueva mención, más o menos encubierta (esto es, haciendo referencia a cuestiones que forman parte de la historia del feminismo, pero sin hacer uso de este término). Este movimiento se da sobre todo entre las comadronas que participaron directamente en los inicios del parto en casa o que fueron aprendices de estas, y que tienen edades comprendidas entre los 43 y los 57 años.

Patricia es una de ellas. Sitúa en un momento histórico preciso la comparecencia de aspectos reivindicativos feministas y, sin embargo, no considera que estas mismas razones estén presentes y sigan siendo válidas en la actualidad, o al menos ya no les atribuye un sentido político feminista:

Ahora no creo que sea tanto una reivindicación de un carácter así, como más político, sino más de mujer, independientemente de la ideología [Patricia, 43 años].

Y más adelante añade:

Entonces creo que es reivindicativo el parto en casa porque forma parte de toda esta parte de salud reproductiva de la mujer, donde nosotras queremos decir qué es lo que queremos para nosotras y nuestra sexualidad, como la menopausia o como que no nos pongan no sé qué o que nos den hormonas porque hemos llegado a la etapa de la menopausia, pero dentro de esto [Patricia, 43 años].

Hemos señalado la dificultad de insertar el parto en casa dentro de las luchas e iniciativas feministas desde los albores de este modelo de atención, conectándolo con el prevalecer de otras reivindicaciones y con los dilemas que plantea para el feminismo el denominado parto natural, y las teorías y prácticas que se relacionan con él. En el caso de las matronas domiciliarias actuales, sin embargo, que parir en casa se asocie (o no) explícitamente con el feminismo parece depender principalmente del significado que se atribuya a este término. Retomando sus discursos, encontramos que aparece como un marco ideológico bastante vago, en un sentido evidentemente despectivo de ideología; como el opuesto complementario del machismo y por tanto como un supuesto deseo de afirmación social de las mujeres en detrimento de los hombres, basado en la convicción de su superioridad; o como reproducción de las relaciones económicas capitalistas en las que se pide se incluyan a las mujeres en igualdad de condiciones. Es así, por ejemplo, en las palabras que pronuncia este matrón en tono de burla, a propósito de las feministas:

[...] queremos que nos den un espacio en esta sociedad patriarcal tan chunga.

Queremos trabajar como los hombres [Ernesto, 36 años]. 
Estas identificaciones llevan a un uso temeroso de las palabras feminismo y feminista, y generan la necesidad de explicarse o, directamente, de utilizar otros términos. Es el caso de las expresiones que inciden en la autonomía de las mujeres, en las herencias del movimiento de salud de las mujeres o en unas reivindicaciones independientes de toda ideología.

El desconocimiento de la multiplicidad teórica feminista -común entre las matronas entrevistadas y al que probablemente han contribuido tanto el triunfo institucional del proyecto feminista liberal, que ha ido ocultando la existencia de otras voces (Méndez 2007), como el afirmarse de nuevos intereses activistas (Braidotti 2004), en gran medida gracias a las luchas de los colectivos lgtbqi- hace que incluso las comadronas que reconocen las raíces feministas del parto en casa muestren cierta reticencia a emplear el término. En sus palabras éste emerge como un término equivoco, confuso, amenazador. Y en efecto podría llegar a considerarse caduco fuera de determinados círculos académicos y militantes, siendo a menudo sustituido por la más amigable y generalmente mal empleada perspectiva de género (Andrieu y Mozo, 2005). El problema estaría, por tanto, en la mayoría de los casos, en cierto desconocimiento de la producción feminista y en su reducción a determinados núcleos teóricos, a grupos concretos o a una línea institucionalizada, que ha incidido especialmente en la incorporación a un mundolaboral, cuya organización y cuyas reglas resultan cada vez más discutibles, y de manera patente para las madres. Condiciones laborales precarizadas y escasez de medidas económicas de apoyo a la maternidad, paternidad y primera infancia constituyen las bases comunes sobre las que se van desarrollando las experiencias de posparto. Si el contexto políticoeconómico no es especialmente favorable al cuidado de niños y niñas pequeños/as, la situación se agrava considerablemente en el momento en que se pretenden respetar de manera literal algunos de los consejos expertos que conforman el heterogéneo campo de la denominada "crianza con apego», en el que participa el parto en casa como modelo de atención inclusivo de la fase anterior y posterior al nacimiento.

\section{PARTO EN CASA, "CRIANZA CON APEGO"Y DERIVAS CONSERVADORAS}

Presentar los nexos del parto en casa con determinadas modalidades de crianza nos permite reflexionar sobre tensiones y contradicciones que han sido también internas al propio feminismo, y que han producido posturas encontradas y dicotomizadas. La maternidad se ha interpretado, así, bien como lugar de resistencia, bien como lugar de inevitable subordinación del que hay que, en la medida de lo posible, sustraerse.

Las matronas domiciliarias tienden a valorar enormemente las experiencias de maternidad y paternidad, atribuyendo una importancia considerable a la infancia y a los primeros años de vida de la persona. Algunas de ellas participan como profesionales en grupos de lactancia; algunas han impulsado y siguen impulsando la creación de grupos de crianza entre madres y padres, a los que pueden ser invitadas puntualmente en calidad 
de expertas; otras incluyen la coordinación de grupos de posparto en su propia oferta de servicios. Se suelen fomentar prácticas de «crianza con apego» como el colecho (en la que el bebé duerme en la cama junto con uno o ambos progenitores); el porteo (uso de fulares y mochilas portabebés); o la lactancia materna exclusiva (no complementada por leche de fórmula), prolongada (a lo largo de los primeros dos años) y a demanda (sin horario fijo). En los casos en los que se ofrecen cursos de preparación prenatal, cuidar de un bebé se presenta como una actividad importante, difícil y necesaria para la sociedad. Y se formula un posicionamiento explícito contra la que se considera una escasa o nula consideración social con la primera infancia. Dedicar tiempo y energía a una persona de pocos meses, amamantar en un espacio público o llevar un bebé consigo a sitios en los que habitualmente no entra, se interpretan como deseables subversiones de la norma y como expresiones de resistencia. No obstante, las experiencias narradas por algunas madres nos obligan a considerar la posibilidad de que determinadas perspectivas teóricas sobre la crianza y los modos de hacer que en ellas se promueven contribuyan a generar situaciones en las que la maternidad se convierte, por enésima vez, en un lugar de subordinación para las mujeres.

De manera muy general podemos definir la crianza con apego como caracterizada por unos modos de hacer que pretenden estar profundamente atentos a las necesidades de niños y niñas. Sus orígenes suelen situarse en los desarrollos teóricos del psiquiatra y psicoanalista John Bowlby, de mediados de los años sesenta ( $c f$. Diez, 2000), que postulaba la necesidad de figuras adultas de referencia o «de apego» para la primera infancia, pero las numerosas interpretaciones y reformulaciones han dado lugar a corrientes y prácticas bastante variadas, y que se adaptan a situaciones personales y familiares. Así, por ejemplo, entre las prácticas más comunes de este modelo de crianza, la lactancia prolongada se traduce en tiempos y estrategias variables, introducción progresiva de la comida y negociación con el hijo o la hija; el contacto con el bebé no es continuado ni exclusivamente materno; el colecho es muy practicado básicamente porque es considerado más cómodo; el porteo es frecuente, pero no excluye otras modalidades como carros o sillas, ni corresponde solamente a la madre. La centralidad de y el profundo respeto por las necesidades infantiles constituye en todo caso el denominador común.

La atención a los recién nacidos, considerados personas vulnerables y dependientes, no necesariamente contradice la atención hacia sus progenitoras. En los cursos de preparación prenatal, de hecho, se hace un esfuerzo continuo por formular discursos no excluyentes y por desmarcarse de toda indicación normativa y moralizante, gracias a unos contenidos en continua evolución y a la promoción activa de debates. No obstante, considerar a la pareja madre-bebé como un «dato primordial» (Mathieu, 1991), a la vinculación temprana como un efecto del contacto «piel con piel», a la lactancia como una actividad sana, fácil y placentera, puede haber supuesto importantes dificultades, 
haber desembocado en un reparto tradicional y nada satisfactorio de tareas en la pareja, y haber resultado pernicioso para la salud de quienes no encajan, por ejemplo, por circunstancias personales, situación sociolaboral o presencia de otros hijos pequeños, con este modelo idealizado. El riesgo de que subrayar las necesidades infantiles se convierta en una «ética reaccionaria del cuidado» (Pérez Orozco, 2011) no puede negarse. Volver a esencializar los cuidados maternos, atribuyéndolos a una supuesta naturaleza altruista femenina, a este ser-para-otros, al olvido de sí misma impuesto por determinadas ideologías y condiciones sociales, y que ha sido tantas veces denunciado por autoras feministas (Lagarde, 2001 [1990]; Rich, 1996 [1978]; Sau, 2004 [1995], entre otras), existe como posibilidad y ha sido experimentado ( $\mathrm{y}$ criticado) por algunas madres.

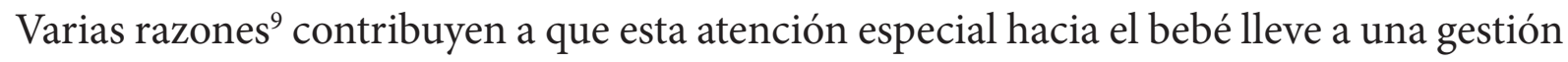
de su cuidado en el seno de la pareja. Esta se traduce en una evidente sobrecarga para ambos miembros y en un aislamiento aún más acentuado para las madres, que puede llegar a extremos claramente insanos. Entre las experiencias de posparto narradas por las madres, dos se distinguen por su especial crudeza. Una es relativa al nacimiento de un segundo hijo, mientras la primera era todavía pequeña; otra se asocia a graves problemas con la lactancia. Ambas podrían resumirse como un choque frontal con la realidad de la crianza, después de una serie de lecturas que elogiaban las virtudes de un modelo de maternidad cuidadoso y atento, que hacía hincapié en la importancia e incluso en la facilidad de la lactancia, en la unidad materno-filial y en el papel del padre como sostén de la díada (madre-hijo), todos ellos argumentos de los que también se sirven las propias comadronas.

Vamos a detenernos brevemente sobre estas dos historias, emblemáticas de unas posibles derivas conservadoras de la crianza con apego.

Lola insiste en que su expectativa, después de un embarazo muy feliz y un parto rápido, era la de «echar fuegos artificiales» y querer mucho a su bebé, según una imagen edulcorada que compara al universo disneyano. En cambio su posparto, y lo repite una y otra vez, fue como "pegarse una hostia». «¿Cómo lo iba a querer, si lo que quería era echarlo por la ventana?», afirma, al recordar la relación inicial con su hijo, que no fue precisamente de amor inmenso e incondicionado. Lola no tuvo un «mal parto», no fue separada de su bebé y no fue víctima de violencia obstétrica, sino de una violencia autoimpuesta, de una agresión a su cuerpo, a su persona, debida a su férrea voluntad de respetar un ideal de

9. No solamente el contexto político-económico no resulta favorable al cuidado de personas altamente dependientes, sino que otros elementos como son la imagen socialmente dominante de la inviolabilidad del espacio doméstico y de la intimidad de la pareja; la gran inversión emocional que conlleva cada embarazo debido, entre otras cosas, al retrasarse de las edades reproductivas y a la reducción del tamaño familiar; y, por último, el recurso generalmente conflictivo a abuelas y abuelos como principal medio para responder a las nuevas necesidades del núcleo familiar contribuyen a una gestión de la crianza repartida básicamente entre madre y padre, y caracterizada por una mayor dedicación de ella. 
madre que, si bien diferente del de su propia madre, se demostraba igualmente estático y exigente. Sin embargo, a pesar de todos sus esfuerzos y de su insistencia estoica en quedarse durante horas y a lo largo de días y noches con su niño pegado al pecho, sus pechos no producían leche:

Y [...] y claro, yo solo sabía que el biberón no se lo podía dar, que el biberón no se lo podía dar y que el biberón no se lo podía dar. Y que no lo podía soltar, porque lo había leído en los libros. Y que tenía que tener la teta todo el día puesta. Yo estuve un día 33 horas sentada en el mismo sitio del sofá, y mi hijo mamando sin parar. O sea mi hijo se cogía de puta madre, yo no tuve grietas, no tuve nada. Mi hijo mamaba, solo que es que no había leche. Esto en los libros decían que no podía pasar [Lola, 41 años].

Dos años después, según una interpretación de malestares, complicaciones o patologías que retoma la propuesta en los cursos prenatales a los que asistió, empezó a entender que era su cuerpo el que canalizaba las contradicciones vividas y expresaba lo más profundo, lo más oculto, lo que ella negaba. La eficacia de la «protesta corporal» (Scheper-Hughes, 2000) se debe, en este caso, a su incontestabilidad, a modalidades afirmativas y perentorias. Aquí el cuerpo no solamente está diciendo algo, sino que está haciendo, está actuando, está impidiendo, en concreto, seguir con un modo de crianza idealizado que no responde a las necesidades particulares de una mujer particular, inserta además en un contexto específico que hace de la crianza un hecho absolutamente individual.

La historia de Bea es extraordinariamente similar, tanto por la reacción de rechazo corporal, en este caso selectivo, a la lactancia, como por los intentos de aplicación literal de lo leído. Bea llega a considerar autónoma una criatura a la que se le ofrece la posibilidad de estar pegada al cuerpo de la madre, porque es allí donde lo tiene todo, «sabe mamar sola, sabe pegarse cuando tiene frío, sabe despegarse cuando tiene calor, sabe buscar la protección, se siente segura», dice. Se refiere a su primer posparto como a un periodo de gran satisfacción y bienestar, y en el que pronto pudo dedicarse a otras ocupaciones, aunque siempre llevando a su niña consigo. Fue solamente después de su segundo hijo que lo leído se hizo inalcanzable. El apoyo de amigas y amigos, experimentado y profundamente agradecido en su parto, no siguió después del nacimiento, por lo que el aislamiento, el alto nivel de autoexigencia, y la pretensión de seguir con el mismo modelo de presencia intensiva y cuidados continuados con ambos hijos, se convirtió en una auténtica tortura, una vez más autoimpuesta:

[Lo leído] lo podía aplicar. Porque era una bebé para mi, entonces, aunque había cosas que me habían removido, pero en realidad ¿esto cómo se hace?, ¿así? Pues asílo hago yo. ¿No? Cuando viene el otro, es imposible, es imposible, ¿sabes? ¿Por qué? Porque hay dos bebés que te están pidiendo dos cosas diferentes y tú solo eres una ¿sabes? Y ahora ya, ¿ahora qué? Y esto fue para 
mi muy frustrante, muy difícil, muy doloroso, yo no dormía, yo no comía, yo no cagaba sin un bebé encima. Terminé desquiciada ¿sabes? Si tú imagínate, si los nazis usaban el tema de no dejarte dormir para volverte loco como un método de tortura ¿no? Yo a mi misma me autotorturaba, ¿sabes? Terminé desquiciada, pesando 40 y pocos kilos [...], terminé muy mal [Bea, 34 años]. Lo interpreta, sin términos medios, como una violación hacia sí misma y una culpabilización doble de las víctimas: su hija y ella. Sus palabras, que inicialmente parecen reproducir frases leídas en un manual, son un crescendo de pena y desazón:

Pero como la sexualidad oral está hasta los tres años y medio, cuatro, que empieza la sexualidad genital, y dentro de la fase de sexualidad oral es tan importante la teta, yo no podía permitirme destetar a mi hija antes de los tres años y medio, ¿sabes? Y entonces había veces que mi hija me pedía de mamar y yo me enfadaba con ella, yo llegaba a enfadarme mucho con ella y a tratar a mi hija muy mal, tía, y era una bebita, ¿sabes?

Además de enfadarse, gritar, despertarse por la noche, su propio cuerpo, su pecho manifestaba un rechazo selectivo hacia la hija, lo cual le generó un profundo sentimiento de culpa, tantas veces señalado para la maternidad, al menos a partir de la creación de la infancia como categoría analítica y periodo necesitado de protección especial. La incapacidad de poner límites, de adaptar las teorías a la realidad cotidiana, de tener en cuenta sus propias necesidades, emociones y deseos, la llevó a sentirse, en última instancia, una «mala madre». La maternidad, a partir de una crítica mordaz a la ausencia de respuestas sociales a las necesidades infantiles, vuelve a tener carácter de sacrificio, de entrega incondicionada y potencialmente masoquista, promovida durante muchos años por las ideologías dominantes (Diez, 2000; Sau, 2004 [1995]).

En ambas historias las matronas se consideran en cierta medida responsables de estas vivencias, por sus discursos en el embarazo y por haber sido incapaces de ofrecer un apoyo adecuado en el posparto. Posparto que, como se repite incansablemente en los cursos prenatales a los que he asistido, sería el gran olvidado por la sanidad, por la sociedad en general y por los propios futuros progenitores, que tienden a centrarse casi exclusivamente en el momento del parto. Las reflexiones propuestas por las matronas en los tres meses que anteceden el nacimiento, que es cuando se imparten estos cursos, parecen haber sido del todo insuficientes en los casos que se acaban de exponer. Cabe señalar, aunque no sea este el lugar para detenernos en su análisis, que los discursos de estas profesionales poseen un grado de complejidad muy elevado, en absoluto reducible a una visión esencialista, edulcorada o simplista del proceso de epp y de la maternidad. Reconocer una sabiduría innata convive, así, con la afirmación de la importancia de informaciones y aprendizajes. Asimismo, se procura evitar todo automatismo. Por 
ejemplo, aunque se hable de efectos hormonales, no se reduce nunca todo a hormonas ni a relaciones unívocas de causa-efecto. Igualmente, aunque a menudo se exalte el parto como un proceso revelador, generador de un conocimiento profundo de una misma, no se pierde de vista en ningún momento lo corporal, lo físico y hasta la trivialidad de algunos aspectos y momentos del epp. La referencia a un principio masculino y otro femenino, finalmente, es en gran medida simbólica, aunque es innegable la facilidad de su asociación con las mujeres de carne y hueso, como naturalmente más cooperativas, respetuosas, cuidadosas. Se generan, por tanto, una serie de ambigüedades, que corren el riesgo de ocultar que se está hablando siempre de tareas, pero también de espacios y de emociones feminizados/masculinizados a lo largo de la historia.

Según advertía Guillaumin, haciendo un guiño a Orwell, «todos los animales son naturales, pero algunos son más naturales que otros» (1978: 13). Señalaba, con ello, la común atribución de tareas «naturales»o «instintivas» a las mujeres, y los efectos perjudiciales que esta suele tener en sus vidas. Subrayaba, asimismo, las consecuencias políticas de servirse del «discurso de la naturaleza» que, independientemente de su finalidad, acaba manteniendo a las mujeres fuera de las relaciones sociales reales, por sus implicaciones de cierre, de inmovilidad, de ausencia de cambio.

\section{A MODO DE CONCLUSIÓN}

A pesar de constituir una práctica muy minoritaria, el parto en casa plantea interesantes desafíos para una lectura antropológica feminista. Se han seleccionado algunos aspectos, haciendo hincapié en las contradicciones, las ambivalencias, las ambigüedades que se generan, con la intención explícita de iniciar una reflexión sobre los nexos entre parto en casa y feminismo, y en la esperanza de desencadenar nuevos debates.

Tanto reconstruir estos nexos a través de una breve genealogía del parto en casa (desarrollada en los dos primeros epígrafes), como proceder a su identificación en la actual asistencia domiciliaria en Andalucía (realizada en los dos siguientes) contribuye a cuestionar e incluso derribar las conclusiones un poco someras de algunas conocidas autoras feministas. Elisabeth Badinter (2011), por ejemplo, liquida el parto en casa definiéndolo como una moda que fracasó y se sirve de un tono sarcástico para ningunear a las que lo eligen. Sin embargo, tal y como hemos pretendido demostrar, de ninguna manera puede reducirse, ni en los años setenta y ochenta ni ahora, exclusivamente a una exaltación ideológica de lo natural y de lo «salvaje», como ella lo etiqueta (id.). Si aportaciones como la de Badinter no contribuyen en absoluto a una discusión fructífera, truncándola con la burla y con la banalización aplicadas a toda práctica que no comparte (entre ellas también la lactancia materna o el rechazo de la píldora como método anticonceptivo), es posible recorrer otros caminos, haciendo emerger las tensiones entre distintos núcleos argumentales. 
Entre las tensiones detectadas, nos parece relevante para el objetivo que nos ocupa destacar que, lejos de resolverse, se encuentra muy presente la contradicción básica entre negar una naturaleza femenina inferiorizada y volver a ella exaltándola. El recurso reiterado del feminismo, con algunas variantes a lo largo de los años, a una naturaleza femenina decontextualizada y universal se debe, siguiendo a Curiel y Falquet (2005), a su atractivo, a su función aliviadora y tranquilizadora, a la capacidad de dejarnos "con una esperanza simple: lo femenino, que siempre ha sido oprimido, un buen día tomará su revancha» (id: 1). O, en palabras de Donna Haraway (1995 [1991]: 227): «[...] la naturaleza o el cuerpo femenino significan demasiado fácilmente el núcleo salvador de la realidad distinguible de las imposiciones del patriarcado, del imperialismo, del capitalismo, del racismo, de la historia y del lenguaje». En concreto, en el ámbito de la asistencia domiciliaria, consideramos que el problema se acentúa cuando los argumentos esencialistas y/o halagadores de lo materno no cumplen aquellas funciones estratégicas positivas mencionadas por autoras que analizan la «retórica del instinto» en el campo de la lactancia materna y del activismo pro lactancia (Ausona, 2016; Massó, 2015). Sería así, por ejemplo, cuando se usan para reforzar la toma de decisiones minoritarias como parir en casa, animar en el momento del parto, vivir en modos placenteros el embarazo o la crianza, o amamantar en un espacio público.

En último término, las implicaciones negativas de cualquier discurso naturalizante podrían superarse al historizar y anclar en lo social las vivencias del epp, de la maternidad y de la paternidad. Tal y como sugería Rosi Braidotti (2003), subrayar una diferencia entre sexos no esencialista sino estratificada y derivada de la historia abre la puerta a cambios sociales más generalizados, que parten de una reconsideración de lo históricamente devaluado al haber sido asociado a las mujeres. Se produciría, así, una politización activa del epp. Sin embargo, en los discursos analizados, las tensiones entre distintos argumentos permanecen, no se resuelven.

Aún admitiendo la presencia de estas tensiones, creemos que lo que puede representar un auténtico escollo a una politización del epp no es tanto la variabilidad de los discursos y las contradicciones detectadas en ellos, sino el prevalecer progresivo de unas razones únicas: las de la evidencia científica. Son estas razones las que ganan peso a nivel social, las que sirven a la hora de sostener la validez y legitimidad de la asistencia domiciliaria, y las que ya predominan de hecho, como se ha señalado, en una de las dos grandes corrientes existentes en Andalucía. Su imposición como paradigma único corre el peligro de empobrecer la riqueza de las contribuciones que nos ha proporcionado hasta ahora el parto en casa como lugar de experimentación. Esto implicaría cancelar o minimizar otras razones que han estado a la base de su desarrollo e infravalorar aspectos de la asistencia que han sido fundamentales para las perspectivas feministas en salud. Una de las consecuencias más preocupantes sería la invisibilización de las relaciones sociales bajo supuestos de cientificidad (Guillaumin, 1978). 
Lo expuesto en estas páginas nos lleva a defender, en definitiva, la tremenda actualidad de insertar la atención perinatal en la agenda feminista. Y no solamente para denunciar la violencia obstétrica y reducir la medicalización de todo el proceso, sino para elaborar nuevos modos de atención, que sean capaces de beneficiarse del trabajo ya desarrollado, a lo largo de los años, por las corrientes de atención domiciliaria que se desarrollaron a partir de finales del siglo pasado. Su contribución más significativa se debe a que no se han limitado a defender un enfoque fisiológico en el parto, como ha ocurrido en las recientes reformas del sistema sanitario (MSC, 2007; Junta de Andalucía, 2010), sino que se han demostrado muy hábil en desvelar las relaciones de poder y reducir los diferenciales de poder, lo que es, en el fondo, uno de los principales baluartes y a la vez reto constante del feminismo (Braidotti, 2004 [2001]). 


\section{REFERENCIAS BIBLIOGRÁFICAS}

Aler Gay, Isabel (2012) “Sociología de la maternidad en España." En Maternidad y salud. Ciencia, conciencia y experiencia. Madrid: Ministerio de Sanidad, Servicios Sociales e Igualdad, pp. 71-126.

Andrieu Sanz, Rosa, y Mozo González, Carmen (2005) "Normalización del 'género’ y problemas de legitimidad de las teorías y luchas feministas". En Antropología feminista y/o del género: legitimidad, poder y usos políticos. Sevilla: Fundación El Monte, Federación de Asociaciones de Antropología del Estado Español, Asociación Andaluza de Antropología, pp. 9-40.

Ausona Bieto, Marta (2016) "Lactancias maternas más allá del año. Críticas, creencias y corporalidad”. Musas 1 (1), pp. 16-32.

Badinter, Elisabeth (2011) La mujer y la madre. Madrid: La esfera de los libros.

Braidotti, Rosi (2003) In metamorfosi. Verso una teoria materialista del divenire. Milano: Feltrinelli.

Braidotti, Rosi (2004) Feminismo, diferencia sexual y subjetividad nómade. Barcelona: Gedisa.

Curiel, Ochy, y Falquet, Jules (2005) "El patriarcado al desnudo. Tres feministas materialistas. Colette Guillaumin-Paola Tabet-Nicole Claude Mathieu”. En Ochy Curiel y Jules Falquet (eds.) El patriarcado al desnudo. Buenos Aires: Brecha Lésbica, pp. 1-18.

DAIA Dones per l'autoconeixement i l'anticoncepció (1979) Maternidad, embarazo y parto. Texto de ponencia, sin publicar.

DAIA. Dones per l'autoconeixement i l'anticoncepció (1981) "Reflexiones sobre una experiencia." En Barbara Ehrenreich y Deirdre English Brujas, comadronas y enfermeras. Historia de las sanadoras. Barcelona: La Sal, pp. 2-4.

De Miguel, Jesús M. (1980) “La sociedad estéril: pautas de control de natalidad." En Michael Kenny y Jesús M. de Miguel (coords.) La Antropología médica en España. Barcelona: Anagrama, pp. 267-293.

Díez, Carmen (2000) "Maternidad y orden social. Vivencias del cambio." En Teresa del Valle (coord.) Perspectivas feministas desde la antropología social. Barcelona: Ariel, pp. 155-185.

Ferreira, Sílvia Lúcia (2008) "El movimiento feminista y la salud de las mujeres: la experiencia de los centros de planificación familiar (CPF) en Catalunya (1976-1982)". Revista Estudos Feministas 16 (3), pp. 785-807.

Guillaumin, Colette (1978) "Pratique du pouvoir et idée de Nature (2). Le discours de la Nature”. Nouvelles Questions Féministes (3), pp. 5-28. 
Kitzinger, Sheila (1988) Embarazo y nacimiento (Tomo I y II). México, D. F.: Interameri. Lagarde, Marcela (2001) Los cautiverios de las mujeres. Madresposas, monjas, putas, presas y locas. México, D. F.: UNAM.

Leboyer, Frédérick (1983) Por un nacimiento sin violencia. México, D. F.: Daimon de Mexico.[1974].

Lellep Fernandez, Renate (1980) "La lactancia materna: progresión de imágenes en desuso." En Michael Kenny y Jesús M. de Miguel (coords.) La antropología médica en España. Barcelona: Anagrama, pp. 295-308

Massó Guijarro, Ester (2015) “Conjeturas (¿y refutaciones?) sobre amamantamiento: teta decolonial”. Dilemata 7 (18), pp. 185-223.

Mathieu, Nicole-Claude (1991) L’anatomie politique. Catégorisations et idéologies du sexe. Paris: côté-femmes.

Méndez, Lourdes (2007) Antropología feminista. Madrid: Sintesis.

Mies, Maria, y Shiva, Vandana (1997) Ecofeminismo. teoría, crítica y perspectivas. Barcelona: Icaria. [1993].

Mocci, Rosalba (1994) "Lassistenza ostetrica nella città di Oristano dalla seconda metà dell'Ottocento ai nostri giorni." En Luisa Orrù y Fulvia Putzolu (coords.) Il parto e la nascita in Sardegna. Tradizione, medicalizzazione, ospedalizzazione, Cagliari: CUEC Editrice, pp. 123-150.

Montes, M. J.; Jiménez-Herrera, M. F.; Castells-Montes, A. y Martorell-Poveda, M. A. (2013) "Ser matrona a mediados del siglo XX. El género como distribuidor de oportunidades y organizador de las emociones.” En Àngel Martínez-Hernáez, Lina Masana, y Susan M. DiGiacomo (coords.) Evidencias y narrativas en la atención sanitaria. Una perspectiva antropológica. Tarragona: URV, pp. 179-198.

Moscucci, Ornella (2003) "Holistic obstetrics: the origins of 'natural childbirth' in Britain.” Postgraduate Medical Journal 79, pp. 168-173

Odent, Michel (1984) Nacimiento renacido. Buenos Aires: Errepar.

Odent, Michel (2001) La cientificación del amor. El amor en la ciencia. Buenos Aires: Creavida. [1999]

Odent, Michel (2008) Ecología prenatal. Buenos Aires: Creavida.

Orrù, Luisa (1994) "Partorire in casa e partorire in ospedale. Testimonianze biografiche orali di donne madri." En Luisa Orrù y Fulvia Putzolu (coords.) Il parto e la nascita in Sardegna. Tradizione, medicalizzazione, ospedalizzazione, Cagliari: CUEC Editrice, pp. 153-242. 
Ortiz Gómez, Teresa (1999) “Las matronas y la transmisión de saberes científicos sobre el parto en la España del S. XIX.” Arenal 6 (1), pp. 55-79.

Pérez Orozco, Amaia (2011) "Crisis multidimensional y sostenibilidad de la vida." Investigaciones Feministas 2, pp. 29-53.

Redacción Farmacosalud.com, "Desde el punto de vista médico, no es recomendable el parto en casa", farmacosalud.com, http://farmacosalud.com/desde-el-punto-de-vistamedico-es-recomendable-el-parto-en-casa [Consultado en septiembre de 2015].

Rich, Adrienne (1996) Nacemos de mujer. La maternidad como experiencia e institución. Madrid: Cátedra.

Ruiz Vélez-Frías, Consuelo (2008) Cartilla para aprender a dar a luz. Madrid: Talasa. [1998].

Ruiz Vélez-Frías, Consuelo (2009) Parir sin miedo. Tegueste: Obstare.

Sau, Victoria (2004) El vacío de la maternidad. Madre no hay más que ninguna. Barcelona: Icaria.

Scheper-Hughes, Nancy (2000) "Il sapere incorporato: pensare con il corpo attraverso una antropologia medica critica.” En Robert Borofsky (coord.) Lantropologia culturale oggi. Roma: Meltemi, pp. 281-292.

Taboada, Leonor (2012) “Consuelo Catalá: una voz inconfundible del feminismo”. MyS. Mujeres y Salud 33, pp. 6-9.

Triolo, Nancy (1994) "Fascist unionization and the professionalization of midwives in Italy: a Sicilian case study". Medical Anthropology Quarterly, New Series 8 (3), pp. 259281.

Triuzzi, Serena (en prensa) “Cambios en la atención perinatal. De derechos de las mujeres a evidencia científica o lo que se pierde por el camino”. En Bálint Ábel Bereményi y David Lagunas (coords.) Simposio 5: Aproximación crítica a la participación y el empoderamiento. Estudios sobre minorías socioculturales y grupos sociales marginalizados". Valencia: FAAE, Asociación Valenciana de Antropología, pp. 97-109.

Valiente Fernández, Celia (2003) "Las políticas para las mujeres trabajadoras durante el franquismo”. En Gloria Nielfa Cristóbal (coord.) Mujeres y hombres en la España franquista: sociedad, economía, política, cultura, Madrid: Instituto de Investigaciones Feministas, Universidad Complutense de Madrid, pp. 145-178.

VVAA. (1988) “Embarazo y nacimiento gozosos”. Integral. Monográfico número 4. [1982]. 


\section{Documentos institucionales}

Estatuto del personal sanitario no facultativo de las instituciones sanitarias de la Seguridad Social, de 1973.

Estrategia de atención al parto normal en el Sistema Nacional de Salud (2007), Ministerio de Sanidad y Consumo.

European perinatal health report: health and care of pregnant women and babies in Europe in 2010 (2013), Euro-Peristat.

Proyecto de Humanización de la Atención Perinatal en Andalucía. (2010), Junta de Andalucía, Consejería de Salud. 